\title{
Análisis documental de obras de ficción: aspectos metodológicos y de aplicabilidad
}

\author{
Análise Documental de obras de ficção: aspectos metodológicos de aplicabilidade
}

Documental analysis of fiction: methodological aspects of applicability

Deise Maria Antonio (1), João Batista Ernesto de Moraes (2)

(1) Faculdade de Filosofia e Ciências - UNESP, - Av. Hygino Muzzi Filho, 737 Marília - São Paulo - Brasil - CEP: 17525-900, guima@marilia.unesp.br. (2) deise@tupa.unesp.br

\begin{abstract}
Resumen
Se discuten los aspectos metodológicos del análisis documental de obras de ficción, con especial énfasis en la aplicación del análisis textual a la identificación de los temas tratados en las historias de cara a la recuperación de la información. Se supone que los procedimientos metodológicos utilizados para la indización de las obras científicas no producen resultados satisfactorios cuando son aplicados a documentos narrativos de ficción. El trabajo tiene como objetivo presentar el recorrido generativo de sentido como un medio para obtener temas en las obras de ficción y su aplicación por medio de los indizadores a una historia de ficción. La metodología utilizada es la de construcción del recorrido generativo de sentido por medio de las estructuras de naturaleza narrativa (la manipulación, la competencia, el desempeño y la sanción) y de discurso (temas y figuras) para apuntar el tema del documento. Los resultados demostraron la posibilidad de aplicación del recorrido generativo de sentido al análisis del contenido documental de las obras de ficción, ya que proporciona efectivamente apuntes de los temas indizados por los indizadores. Varias cuestiones relacionadas con este procedimiento requieren una mayor clarificación y sería necesario un estudio preliminar con profesionales a modo de proyecto piloto.
\end{abstract}

Palabras clave: Análisis Documental. Recorrido generativo de sentido. Texto narrativo de ficción. Indización

\section{Introdução}

Este trabalho tem como objetivo o estudo da análise documental de obras de ficção utilizando o percurso gerativo de sentido como uma ferramenta que visa a contribuir para a análise documental de conteúdo, seu processo e descrição dos aspectos intrínsecos do documento, investigando, também, os procedimentos e ações que os profissionais indexadores utilizam nas unidades de informação para exprimir 0 conteúdo das obras de ficção por meio da Análise Documental.

\begin{abstract}
The methodological aspects of the content analysis of fiction with information retrieval purposes are discussed with a focus on the study of textual analysis for the identification of the themes treated in stories. It is assumed that the methodological procedures used for indexing scientific works do not produce satisfactory results when applied to narrative fiction documents. The aim of this paper is to present the gerative sense course as a methodology to extract themes from works of fiction, and to study its application to the indexing of tales by indexers. The methodology used is the construction of gerative sense course, identifying both the narrative level structures (manipulation, competence, performance and punishment) and the discourse level (themes and figures) in order to obtain the theme of the document. The results demonstrated the feasibility of the application of the gerative sense course to the documentary content analysis of works of fiction, in the sense that it provided a clear annotations of the theme of the document that was being indexed by the cataloguers. Several questions related to this procedure require further clarification and also a preliminary study with professionals in the form of a pilot project.
\end{abstract}

Keywords: Document analysis. Generative sense course. Narrative fiction. Indexing.

De acordo com a concepção de análise documental, a extração e representação da informação podem apresentar uma dimensão de forma ou de conteúdo. Para a realização desta pesquisa a base epistemológica utilizada foi a da Analyse Documentaire que tem orientação francesa com reflexões na área científica da Espanha e do Brasil. O foco centralizador é o tratamento temático em si, ou seja, a explicitação dos procedimentos voltados para a identificação e seleção dos conceitos para posterior representação. Esta representação é realizada por meio de critérios previamente estabelecidos 
compreendendo procedimentos para sua etapa analítica e sintética.

\section{Percurso gerativo de sentido}

O percurso gerativo de sentido é uma sucessão de patamares, com suas descrições adequadas, que demonstram a produção e interpretação do sentido de um texto, ou documento, sendo um processo que parte do simples para o complexo.

Segundo Fiorin (1999) "a noção de percurso gerativo de sentido constitui um simulacro metodológico para explicar o processo de entendimento, em que o leitor precisa fazer abstrações, a partir da superfície do texto, para poder entendê-lo". Isso contribui para que a análise e compreensão não residam apenas em construções frasais, ou seja, em unidades linguísticas frasais como de sujeito e objeto, mas na compreensão global do texto.

Para tanto, as noções funcionais como as de sujeito e objeto permanecem com uma relação com a abordagem frasal, mas são reprojetadas para determinar papéis narrativos que só adquirem seu verdadeiro alcance no âmbito global do texto. Isso demonstra que o autor não opera mais com noções linguística, mas com noções semióticas (Tatit, 2007).

O estudo do sentido construído no âmbito do texto tem como precursor o lexicólogo Algirdas Julien Greimas que a chamou de "semântica estrutural" (1966), logo após de semiótica. Estudiosos como Vladimir Propp e Noan Chomsky foram importantes para o desenvolvimento do trabalho de Greimas. Do primeiro o lexicólogo utilizou o modelo de análise do conto maravilhoso russo para lançar sua teoria narrativa na qual demonstrou ser possível uma abordagem sintáxica do texto integral. Do segundo algumas equivalências com a gramática gerativa acerca da concepção do modelo descritivo em níveis (elementos mais abstratos e gerais aos mais concretos e particulares). Na perspectiva gerativa de Greimas as unidades existentes na superfície do texto estariam enriquecidas por articulações localizadas em patamares mais profundos, entre categorias mais simples e abstratas, reveladas somente pelo procedimento descritivo.

Ainda, no sentido do âmbito do texto, importante ressaltar que Greimas queria atingir a meta descrita por Louis Hjelmslev (1975) de "forma de conteúdo" que seria como uma estrutura geral da significação inerente aos textos, tanto verbais como não-verbais.

Observa-se, portanto, que a semiótica (Tatit, 2007, p. 189):
Concebe uma teoria para a análise do conteúdo humano que se manifesta em dimensão transfrasal, independente da configuração textual escolhida para a sua organização e difusão. Esse conteúdo pode surgir como literatura, filme, pintura, música ou até como linguagem coloquial; tudo isso é passível de descrição semiótica.

\subsection{Esquema do percurso}

Diante do exposto, utilizamos o modelo de patamares proposto por Fiorin (1999):

\begin{tabular}{lll}
\hline & $\begin{array}{l}\text { Componente } \\
\text { sintático }\end{array}$ & $\begin{array}{l}\text { Componente } \\
\text { Semântico }\end{array}$ \\
\hline $\begin{array}{l}\text { Estruturas } \\
\text { sêmio- } \\
\text { narrativas }\end{array}$ & $\begin{array}{l}\text { Nível profundo } \\
\text { Sintaxe } \\
\text { fundamental }\end{array}$ & $\begin{array}{l}\text { Semântica } \\
\text { fundamental }\end{array}$ \\
\cline { 2 - 3 } & Nível de Sintaxe & Semântica \\
& Superfície narrativa & narrativa \\
\hline Estruturas & Sintaxe discursiva & Semântica \\
discursivas & Discursivização & discursiva \\
& (actorialização, & Tematização \\
& temporalização, & Figurativização \\
& espacialização) & \\
\hline
\end{tabular}

Tabela I. Modelo de patamares (Fiorin, 1999)

Cada nível possui um componente sintático e um componente semântico. A sintaxe estuda a estrutura do vocábulo, e a semântica as regras que presidem às relações entre os vocábulos, as construções das orações e às relações interoracionais.

A sintaxe "dos diferentes níveis do percurso gerativo é de ordem relacional, ou seja, é um conjunto de regras que rege o encadeamento das formas de conteúdo na sucessão do discurso" (Fiorin, 1999, p. 18).

\subsubsection{Nível fundamental}

A semântica de nível fundamental congrega as categorias semânticas que constituem a base de construção do texto.

Nas estruturas fundamentais as categorias semânticas "que ordenam os conteúdos do texto de maneira mais geral e mais abstrata. Para que possa compreender, entretanto, o valor de cada categoria, há que se buscar elementos nos outros níveis mais concretos do texto" (Moraes, 2007).

Ela tem como fundamento a diferença, a oposição, mas não qualquer oposição, pois, traços comuns precisam existir para estabelecer essa diferença. E, abrange, também, as operações de negação e asserção que ocorrem na sucessividade do texto. 
A semântica e a sintaxe do nível fundamental representam o instância inicial do percurso gerativo e procuram explicar os níveis mais abstratos da produção, do funcionamento e da interpretação do discurso. (Fiorin, 1999, p. 20).

\subsubsection{Nível narrativo}

A sintaxe narrativa é definida como mudanças de estado em termos de conjunção e disjunção, sendo formada por dois tipos de enunciados elementares: enunciados de estado e enunciados do fazer.

Eles enunciados são explicitados por Fiorin (1999, p. 21) como:

\begin{abstract}
a) Enunciados de estado: são os que estabelecem uma relação de junção (disjunção ou conjunção) entre um sujeito e um objeto (no enunciado "Aurélia é rica", há uma relação de conjunção, indicada pelo verbo ser, entre um sujeito "Aurélia" e um objeto "riqueza"; em "Seixas não é rico", há uma relação de disjunção, revelada pela negação e pelo verbo ser, entre um sujeito "Seixas" e um objeto "riqueza");
\end{abstract}

b) Enunciados de fazer: são os que mostram as transformações, os que correspondem à passagem de um enunciado de estado a outro (no enunciado "Seixas ficou rico", há uma transformação de um estado inicial "não rico" num estado final "rico").

Existem duas formas de narrativas mínimas caracterizadas pela privação e a de liquidação da privação. Na privação o estado conjunto que existe passa a um estado final disjunto (família rica que fica pobre). Na liquidação da privação acontece o contrário, o estado inicial é o disjunto e o final conjunto (pessoa pobre que fica rica).

Nessa perspectiva, os textos não são narrativas mínimas, são narrativas complexas onde os enunciados de estado (fazer e ser) estão hierarquicamente organizados, tendo como estrutura uma sequência canônica composta por quatro fases: manipulação, competência, performance e sanção.

- Manipulação: um sujeito agora sobre outro para levá-lo a querer e/ou dever fazer alguma coisa. O sujeito é um papel narrativo e não, necessariamente, uma pessoa. São vários os tipos de manipulação aqui descritos os quatro mais comuns: tentação, intimidação, sedução e provocação.

- Competência: o sujeito que realiza a narrativa é dotado de um saber e ou poder fazer.

- Performance: fase em que se dá a transformação central da narrativa.

- Sanção: última fase onde há a constatação de que a performance se concretizou. A sanção pode ser cognitiva se há o reconhecimen- to que a competência se realizou; ou sanção pode ser pragmática, com prêmios e castigos.

Moraes (2007) salienta que

A sequência canônica não implica num formato pré-definido nos quais todos os textos narrativos devem se encaixar, ao contrário, algumas fases podem apenas ser pressupostas, ou ter um destaque maior do que as outras.

\subsubsection{Nível discursivo}

No nível narrativo as formas abstratas do nível narrativo são revestidas de termos concretos através dos temas e das figuras. Essa concretização se dá por meio da semântica discursiva que reveste as mudanças de estado do nível narrativo.

Os esquemas narrativos abstratos podem estar revestidos com temas e com figuras.

Os textos figurativos "produzem um efeito de realidade, e por isso representam o mundo, criam uma imagem do mundo, com seus seres, seus acontecimentos"; os textos temáticos "explicam as coisas do mundo, ordenam-nas, classificam-nas, interpretam-nas, estabelecem relações e dependências entre elas, fazem comentários sobre suas propriedades" (Fiorin; Savioli, 2003, p. 89).

Assim como as figuras, "os temas também se encadeiam em percursos, isto é, em conjuntos organizados. São os percursos temáticos. Para apreender o tema geral, é preciso perceber esse encadeamento dos temas e depreender a unidade subjacente à diversidade" (Fiorin; Savioli, 2003, p. 101).

\subsection{Linguística textual: percurso temático} e figurativo

Existem duas formas básicas de discurso: o que são concretos e os que são abstratos. Esses termos não são termos polares que fazem oposição, mas constituem um continuum, que gradualmente caminha do abstrato para o concreto.

Dessa forma, podemos caracterizar que o discurso quando é concreto é construído com figuras, ou seja, é figurativo. E, quando é abstrato, é construído por temas, ou seja, ele é temático.

Os textos figurativos remetem a algo do mundo natural, remetem a algo da realidade, representam o mundo, criam imagens desse mundo, dos seres que compõem esse mundo. Quando falase mundo real devemos pensar também no mundo construído, no caso, o texto de ficção onde coisas tem pernas, olhos e falam.

O tema é um (Fiorin, 1999, 65) 
Investimento semântico, de natureza puramente conceptual, que não remete ao mundo natural. Temas são categorias que organizam, categorizam, ordenam os elementos do mundo natural: elegância, vergonha, raciocinar, calculista, orguIhoso, etc.

Dependendo do grau de concretude dos elementos narrativos teremos dois tipos de textos: os figurativos e os temáticos.

Os textos figurativos criam um efeito do real, construindo um simulacro da realidade, representando a forma e o mundo. Enquanto que os temáticos tentam explicar a realidade, classificando-a e ordenando-a.

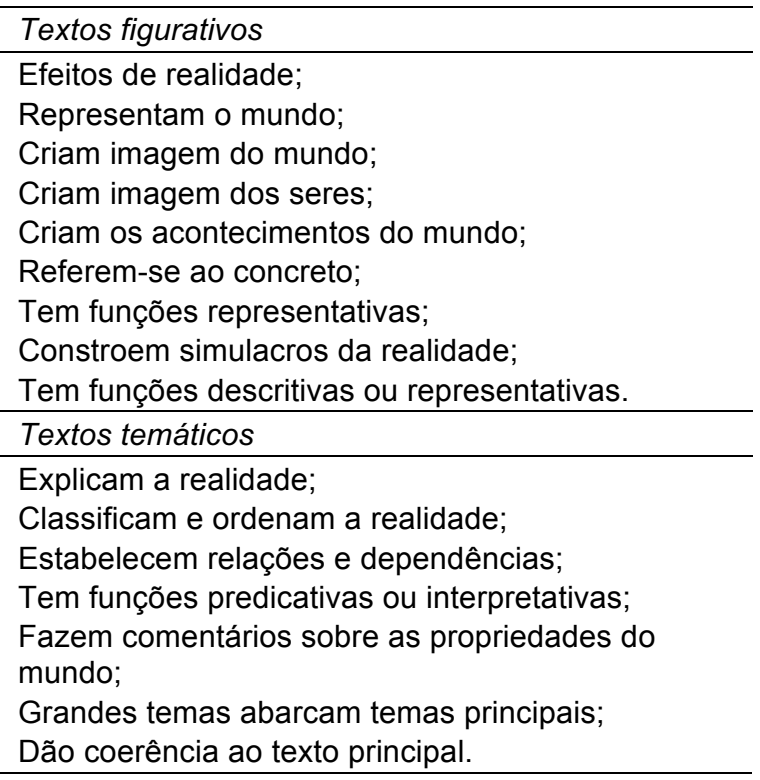

Tabela II. Textos figurativos v. temáticos

Um texto nunca é totalmente figurativo, ou totalmente temático, fala-se em predominância, e não em absolutismo de termos, pois eles coexistem, marcados pela dominância de elementos abstratos ou concretos, e não da exclusividade.

\section{De acordo com Fiorin (1999, p. 67)}

em todo texto, temos um nível de organização narrativa, que será tematizado. Posteriormente, o nível de organização temática poderá ou não ser figurativizado. O nível temático dá sentido ao figurativo e o nível narrativo ilumina o temático. A tematização pode ser manifestada diretamente, sem a cobertura figurativa. Temos então os textos temáticos. No entanto, não há texto figurativo que não tenha um nível temático subjacente, pois este é um patamar de concretização do sentido anterior à figurativização.

\subsubsection{Percurso temático e figurativo}

As figuras no texto estabelecem redes de relações entre si. Para a análise textual o que é mais importante e esse encadeamento das figuras, chamado por Fiorin $(1999, \mathrm{p}, 70)$ de tecido figurativo. Essa rede relacional, esse encadeamento é chamado de percurso figurativo. Ainda para o autor

para que um conjunto de figuras ganhe um sentido, precisar ser a concretização de um tema, que, por usa vez, e o revestimento de enunciados narrativos. Por isso, ler um percurso figurativo é descobrir o tema que subjaz a ele.

Um texto pode ter mais de um percurso figurativo, isso vai depender dos temas que se queira manifestar. Ele deve manter uma coerência interna, pois a quebra de coerência produz a chamada inverossimilhança no texto (Moraes, 2007):

Nos textos narrativos de ficção, essa coerência entre as figuras torna-se essencial, de modo que o leitor, ao ter contato com um texto, possa através desse jogo de figuras ou conexões, entender o contexto em que se insere o mesmo, e a partir daí extrair os temas.

O encadeamento dos temas é chamado de percurso temático, ocorrendo apenas nos textos temáticos. Nos percursos temáticos (Fiorin; Savioli, 2003, p. 101)

é preciso perceber esse encadeamento dos temas e depreender a unidade subjacente à diversidade. Os encadeamentos temáticos também devem manter uma coerência interna. Quebrá-la significa construir um texto incoerente ou alterar o tema geral.

O elemento amalgamador do sentido para a construção os percursos temáticos e figurativos é a isotopia.

\subsubsection{Isotopia}

A isotopia seria o plano de leitura de um texto. O modo com que esse texto deve ser lido, que para a análise do discurso é denominado de recorrência do mesmo traço semântico ao longo de um texto.

É um processo de construção do sentido na dimensão sintagmática do texto oriundo de uma espécie de controle que os semanas das palavras empregadas exercem uns sobre os outros (Tatit, 2007).

Do termo isotopia, também vocábulo derivado da química, "isótopo" designa os elementos do mesmo número atômico, mas que tem massas diferentes. O conceito é o mesmo para o texto, a isotopia daria a possibilitada das diversas leituras que o leitor pode fazer de um texto, pois elas 
já estariam intrínsecas no texto pela coerência semântica que lhe imprime reiteração, redundância, repetição, recorrência de traços semânticos ao longo do discurso. As diversas leituras que o texto aceita já estariam inscritas nele.

\section{A indexação de contos de ficção}

As diferenças existentes entre um texto científico e um texto narrativo de ficção foram apontadas por profissionais bibliotecários em pesquisa realizada por Antonio (2008) como sendo:

1. Peculiaridade: tipologia textual;

2. Finalidade da obra: técnicas direcionada para o estudo; ficção direcionada para ao lazer;

3. Especificidade da obra: técnica mais objetiva; ficção exige um conhecimento prévio do indexador;

4. Consistência e localização de dados: nas obras técnicas os dados de publicação são mais padronizados, por exemplo, sumário; índices; resumo; bibliografia; enquanto as obras de ficção por vezes essas informações são inexistentes, como os próprios dados de catalogação na fonte;

Considerando a atividade de indexação, as dificuldades apontadas foram:

1. Inexistência de política de indexação que contemple obras narrativas de ficção;

2. Falta de tempo: pois se tratarem de obras extensas e o texto não contemplar uma estrutura forma pré-definida (introdução, objetivo, referencial teórico, etc.);

3. Falta de conhecimentos específicos sobre a obra;

4. Inexistência de instrumentos como vocabulário controlado e tesauros específicos para obras de ficção;

5. Quando da catalogação cooperativa: falta de informações da publicação no registro matriz.

Acerca dos procedimentos metodológicos para a indexação de obras de ficção percebe-se a necessidade e importância da "desautomatização" de procedimentos e da substituição dos processos intuitivos por procedimentos metodologicamente previsíveis e defensáveis" (Moraes, Guimarães e Guarido, 2007). Pois, os procedimentos metodológicos utilizados para a indexação são satisfatoriamente aplicáveis ao texto científico devido suas características de tipologia, mas e quanto aos documentos narrativos ficcionais?
Nesta perspectiva foi proposto a indexadores proficientes que por meio da construção do percurso gerativo de sentido, percurso temático e figurativo, fosse realizado o levantamento de temas de um conto narrativo.

Para a escolha do percurso gerativo de sentido como meio para a extração de temas foi levado em consideração à tipologia textual das obras de ficção.

\subsection{Tipologia textual}

Considerando que os tipos textuais são também um meio "para determinar as condições em que se formulam as expectativas que conduzem a própria compreensão" (Moraes, Guimarães e Guarido, 2007), a proposta de Van Dijk acerca da estrutura textual foi à adotada para orientar este trabalho.

O autor trabalha com a noção de superestrutura que seriam as estruturas globais responsáveis, independentemente do conteúdo, pela caracterização do tipo do texto. Os textos se adaptariam a esses esquemas formais que são adquiridos culturalmente. Segundo essa noção, esquemas prévios devem ser seguidos para a construção de um texto e, os mesmos fazem com que o leitor tenha a compreensão no ato da leitura. Seriam esses esquemas que caracterizariam a tipologia do texto.

Van Dijk (1987) explica que

subjacentes às informações linguísticas da estrutura de superfície existem macroestruturas de organização em termos de categorias que funcionam como esquemas (frames) organizacionais armazenados na memória. Através desses esquemas, torna-se possível à reintegração da informação nova à prévia e a reformulação de hipóteses. Constitui a forma lógica de um texto, o nível cognitivo. É o nível do conteúdo, dos aspectos semânticos, nos quais tema e tópico definem a representação do texto.

No nível superficial é onde acontece o processamento da organização da estrutura linguística, onde se localizam as microestruturas (estrutura local de um texto) compondo as proposições básicas do texto que proporcionam, por meio de suas relações, a coerência do texto. A coesão é definida pela relação das estratégias e processos sintáticos entre as proposições que estabelecem, também, a tessitura do texto.

Segundo Fávero e Koch (1988) citados por Moraes, Guimarães e Guarido (2007) três seriam os critérios para a verificação de uma tipologia textual:

- Pragmática (macroatos de fala e atualização em situações comunicativas); 
- Esquemática global (Superestrutura de Van Dijk);

- Linguística de superfície (Marcas sintéticosemânticas).

Os quais oferecem subsídios para a classificação dos textos em: narrativos, descritivos, expositivos (explicativos), argumentativos "stricto sensu", injuntivos (diretivos) e predicativos.

De acordo com o exposto, considerou-se para a pesquisa o conto classificando-o como texto narrativo considerando como critério de análise: a superestrutura: na narrativa predominam as ações. Na estrutura clássica da narrativa, a situação espacial e temporal, bem como as personagens e os contextualizadores, são introduzidos no resumo; seguem-se os acontecimentos, que envolvem a complicação, a avaliação e a resolução; a macroestrutura: o tema envolve uma pessoa, um ser animado, ou uma coisa definida antropologicamente. Pressupõe uma idéia de ação, de mudança de estado, de transformação ou de acontecimento. A sequência temporal é fundamental; e a dimensão linguística de superfície: predominam relações subordinativas, com um verbo de mudança no passado e indicadores de tempo e lugar.

\subsection{Construção do percurso gerativo de sentido por indexadores}

Foi proposto a indexadores proficientes de três importantes unidades de informação da Universidade Estadual Paulista "Júlio de Mesquita Filho" (São Paulo, Brasil) que possuem como característica em comum acervo de livros de ficção, pós-graduação na área de literatura, a análise do Conto "O Torcedor", do autor Carlos Drummond de Andrade.

As estruturas analisadas foram as de nível narrativo e nível discursivo.

A definição de mudanças de estado em termos de conjunção e disjunção (manipulação, competência, performance e sanção) foram analisadas e identificadas pelos profissionais na busca da articulação narrativa existente no conteúdo organizado do texto. E, as figuras e os temas, de cada trecho da sequência canônica, extraídos para a desconstrução dos esquemas narrativos abstratos para a definição da articulação entre as categorias por meio de subtemas de cada mudança de estado e tema geral ao concluir a análise.

Todos os participantes da pesquisa identificaram a sequência canônica na ordem que se segue: manipulação, competência, performance e sanção. Os trechos correspondentes a cada mudança de estado foram identificados no conto e transcritos em tabelas. Na realização da atividade analítica da transcrição dos indexadores observaram-se pequenos graus de diferença na identificação nas etapas narrativas. O grau de diferença concentrou-se em palavras, conjunto de palavras e frases, apresentando a variação de um parágrafo na execução de um dos indexadores.

Exemplo (Indexador 1):

- Identificação da sequência canônica (Tabela III).

- Subtemas extraídos da aplicação do percurso temático e figurativo: jogo de futebol, cidade e jogo de futebol, jogo de futebol e comemoração, jogo de futebol e bagunça, alegria da vitória, alegria do torcedor, manifestação da torcido de futebol, retorno à realidade.

- Tema geral: partida de futebol .

No que dizem respeito às estruturas discursivas, os indexadores apresentaram distinções na identificação e apresentação dos temas e figuras. As figuras apresentaram uma coincidência de respostas sendo elas em sua maior parte semelhantes. Nos temas observou-se maior grau de diferença de respostas. Quanto aos subtemas e tema geral similaridade nas respostas.

Os indexadores apresentaram dificuldades na compreensão das etapas narrativas. Entende-se que este fato ocorreu porque as instruções constantes no instrumento de coleta não demonstraram exemplos, mas apenas aspectos teóricos.

No texto analisado pelos indexadores pode-se perceber que os temas e figuras resultaram em percursos temáticos e figurativos que representaram o tema do texto.

\section{Considerações finais}

A análise documental de obras de ficção depende de procedimentos metodológicos que proporcionem os elementos necessários para qualidade da indexação.

Este primeiro estudo de aplicabilidade do percurso gerativo de sentido com indexadores abre uma nova perspectiva para os estudos até então realizados no âmbito teórico da semântica discursiva aplicada a análise documental. 


\begin{tabular}{|l|l|l|}
\hline Manipulação & $\begin{array}{l}\text { 1 No jogo de decisão do campeonato, Eváglio torceu pelo Atlético Mineiro, não porque fosse atleticano ou mineiro, mas porque } \\
\text { receava o carnaval nas ruas se o Flamengo vencesse. Visitava um amigo em bairro distante, nenhum dos dois tem carro, e ele } \\
\text { previa que a volta seria problema. } \\
\text { 2 O Flamengo triunfou, e Eváglio deixou de ser atleticano para detestar todos os clubes de futebol, que perturbam a vida urbana } \\
\text { com suas vitórias. . Saindo em busca de táxi inexistente, acabou se metendo num ônibus em que não cabia mais ninguém, e } \\
\text { havia duas bandeiras rubro-negras para cada passageiro. E não eram bandeiras pequenas nem torcedores exaustos: estes } \\
\text { parecia terem guardado a capacidade de grito para depois da vitória. }\end{array}$ \\
\hline Tema (elementos abstratos) & Figura (elementos concretos) \\
\hline Decisão & Jogo; Campeonato \\
\hline Torceu & Eváglio; Atlético Mineiro; \\
\hline Receava & Carnaval nas Ruas \\
\hline Vencesse & Flamengo \\
\hline Visitava & Amigo; Bairro Distante; Carro \\
\hline Triunfou; Detestar; Perturbavam & Flamengo; Eváglio; Clubes de Futebol; Vida Urbana; Vitória \\
\hline $\begin{array}{l}\text { Saindo em busca; Acabou se metendo; Cabia; Havia; Guardado a } \\
\text { Capacidade }\end{array}$ & $\begin{array}{l}\text { Táxi; Ônibus; Ninguém; Duas bandeiras rubro-negras; Passageiro; Bandeiras } \\
\text { pequenas; Torcedores exaustos; Grito. }\end{array}$ \\
\hline Tema: Jogo de Futebol; Cidade e Jogo de Futebol; Jogo de Futebol e Comemoração; Jogo de Futebol e Bagunça \\
\hline
\end{tabular}

\begin{tabular}{|l|l|l|}
\hline Competencia & $\begin{array}{l}3 \text { Eváglio sentiu-se dentro do Maracanã, até mesmo dentro da bola chutada por 44 pés. A bola era ele, embora ninguém } \\
\text { reparasse naquela esfera humana que ansiava por tornar a ser gente a caminho de casa. } \\
4 \text { Lembrando-se de que torcera pelo vencido, teve medo, para não dizer terror. Se lessem em seu íntimo o segredo, estava } \\
\text { perdido. Mas todos cantavam, sambavam com alegria tão pura que ele próprio começou a sentir um pouco de flamengo dentro } \\
\text { de si. Era o canto? Eram braços e pernas falando além da boca? }\end{array}$ \\
\hline Tema (elementos abstratos) & Figura (elementos concretos) \\
\hline Sentiu-se dentro; Dentro; Chutada; & Eváglio; Maracanã; Bola; 44 pés; Bola \\
\hline Ninguém reparasse; Ansiava por tornar & $\begin{array}{l}\text { Esfera humana; } \\
\text { Gente; } \\
\text { Caminho de Casa }\end{array}$ \\
\hline Lembrando-se; torcera; vencido; Estava perdido & Medo; Terror; Íntimo; Segredo \\
\hline $\begin{array}{l}\text { Sentir um pouco; } \\
\text { flamengo dentro de si; }\end{array}$ & $\begin{array}{l}\text { Cantavam; Sambavam; Alegria; Flamengo; Canto; Braços; } \\
\text { Pernas }\end{array}$ \\
\hline Falando além da boca & \\
\hline Tema: Alegria da Vitória & \\
\hline
\end{tabular}

\begin{tabular}{|l|l|l|}
\hline Performance & $\begin{array}{l}\text { 4 A emanação de entusiasmo o contagiava e transformava. } \\
\text { 4 Marcou com a cabeça o acompanhamento da música. Abriu os lábios, simulando cantar. Cantou. Ao dar fé de si, disputava à } \\
\text { morena frenética a posse de uma bandeira. Queria enrolar-se no pano para exteriorizar o seu partidário que pulava em suas } \\
\text { entranhas. A moça em vez de ceder o troféu, abraçou-se com Eváglio e beijou-o na boca. Estava batizado, crismado e ungido: uma } \\
\text { vez flamengo, sempre flamengo. }\end{array}$ \\
\hline Tema (elementos abstratos) & Figura (elementos concretos) \\
\hline Emanação de entusiasmo & Contagiava; Transformava \\
\hline Marcou; Acompanhamento da música; & Cabeça; Abriu os olhos; Cantar; \\
\hline Ao dar fé de si; Exteriorizar o seu partidário; Pulava em suas entranhas; & $\begin{array}{l}\text { Disputava à morena frenética; A posse de uma bandeira; Queria } \\
\text { enrolar-se no pano; }\end{array}$ \\
\hline \multicolumn{2}{|l|}{ Boça em vez de ceder o troféu; Abraçou-se a Eváglio; Beijou- na } \\
\hline Estava batizado, crismado e ungido. Uma vez flamengo, sempre flamengo \\
\hline Tema: Alegria do Torcedor; Manifestação da Torcido de Futebol \\
\hline
\end{tabular}

\begin{tabular}{|l|l|l|}
\hline Sansão & $\begin{array}{l}5 \text { O pessoal desceu na Gávea, empurrando Eváglio para descer também e continuar a festa, mas Eváglio mora em Ipanema, e já com o } \\
\text { pé no estribo se lembrou. Loucura continuar flamengo a noite inteira à base de chope, caipirinha, batucada e o mais. Segurou firme na } \\
\text { porta, gritou: "Eu volto, gente! Vou só trocar de roupa" e, não se sabe como, chegou intacto ao lar, já sem compromisso clubista. }\end{array}$ \\
\hline Tema (elementos abstratos) & Figura (elementos concretos) \\
\hline Já com o pé no estribo se lembrou; Eu volto gente & $\begin{array}{l}\text { Pessoal desceu na Gávea; Empurrando Eváglio; } \\
\text { Eváglio mora em Ipanema; Loucura; Chope; Caipirinha;Batucada; } \\
\text { Gritou;Trocar de Roupa }\end{array}$ \\
\hline Chegou intacto & Lar \\
\hline \multicolumn{2}{|l|}{ Compromisso clubista } \\
\hline Tema: Retorno a Realidade & \\
\hline
\end{tabular}

Tabela III. Análise do conto "O torcedor": identificação da sequência canônica

O percurso gerativo de sentido, em termos conceituais, demonstrou exequibilidade para o Levantamento do tema do texto. Sabemos que várias questões relacionadas a aplicação deste procedimento carecem de maior aprofundamen- to e investigação. De modo que foram apresentados neste primeiro momento os aspectos teóricos da proposta da aplicação e um preliminar estudo com os profissionais. 
Espera-se avançar o estudo aqui demonstrado com a abordagem de outros aspetos importantes para a atuação profissional no que diz respeito a indexação de obras de ficção

\section{Referencias}

Antonio, D. M. (2008). O percurso gerativo de sentido aplicado à análise documental de textos narrativos de ficção perspectivas de utilização em bibliotecas universitárias. 2008. 137f. Marília: Universidade Estadual Paulista, Faculdade de Filosofia e Ciências, 2008. Dissertação (Mestrado).

Fávero, L. L.; Koch, I. (1988). Linguística textual: introdução. 2. ed. São Paulo: Cortez, 1988.

Fiorin, J. L. (1999). Elementos de análise do discurso. São Paulo: Contexto, 1999.

Fiorin, J. L.; Savioli, F. P. (2003). Lições de texto: leitura e redação. São Paulo: Ática, 2003.

Greimas, A. (1975). Sobre o sentido: ensaios semióticos. Petrópolis: Vozes, 1975.

Hjelmslev, L. (1975). Prolegômenos a uma teoria da linguagem. São Paulo: Perspectiva, 1975.

Moraes, J. B. E. ; Guimarães, J.A.C. ; Guarido, M. D.M. (2007). Análisis documental de contenido de textos narrativos: bases epistemológicas y perspectivas metodológicas. // Francisco Javier García Marco (Org.). Avances y perspectivas en sistemas de información y documentación en entorno digital. Zaragoza: Prensas Universitarias de Zaragoza, 2007. 93-100.

Moraes, J. B. E.; Guimarães, J.A.C. (2006). Análisis documental de contenido de textos literarios narrativos: en busca del diálogo entre las concepciones de aboutness/meaning y de recorrido temático/recorrido figurativo. // Scire. Zaragoza. (2006).

Propp, VI. (1983). Morfologia do conto. Lisboa: Veja, 1983.

Tatit, L. A. (2002). Abordagem do texto. // Fiorin, J. L. (Org.). Introdução à linguística. São Paulo: Contexto, 2002.

Van Dijk, T. A. (1987). Gramáticas textuais e estruturas narrativas. // Chabrol, C. et al. Semiótica narrativa e textual. São Paulo: Cultrix, 1987.

Recibido: 2010-04-15. Revisado: 2010-07-11. Aceptado: 2010-07-12 